\title{
Improving Training Aircraft Utilization in Collegiate Flight Programs: A Case Study at Purdue University
}

\author{
John H. Mott and Darcy M. Bullock \\ Purdue University
}

\begin{abstract}
Aircraft fleets employed for student training in collegiate aviation programs are operated to varying degrees of efficiency, a metric that is influenced by such factors as scheduling, weather, and maintenance requirements. Recent research focusing on the utilization rate of the Cirrus training fleet at Purdue University indicated an average rate of 24\% (Avery, 2014). An improvement in the efficiency of the scheduling of the Cirrus fleet would subsequently allow an accurate determination of the degree of excess capacity in the system. This excess capacity should ideally be treated as an asset that could be used to support an increase in enrollment in the Professional Flight program, a concept that could ultimately result in a reduction of student flight fees by spreading fixed costs across a larger student base, thereby improving the overall affordability of the program. This article examines the overall Cirrus utilization at Purdue, identifies both supply and demand components that affect the metric, and proposes recommendations for improving utilization. Through application of the recommendations developed in this paper, it is estimated that the Professional Flight program can accommodate a $20 \%$ increase in enrollment, resulting in significant incremental revenue which can be allocated to support additional program growth, reduce student fees, and provide internal employment opportunities for Aeronautical Engineering Technology students studying to obtain their Airframe and Powerplant Mechanic certification. Implementation and monitoring of these recommendations is being integrated into an undergraduate course in aviation managerial economics to provide additional experiential educational opportunities for Aviation Technology students.
\end{abstract}

\section{Introduction}

The Purdue University Professional Flight Program is housed within the Department of Aviation Technology, which itself resides in the Purdue College of Technology. The College of Technology consists of five departments and one school, and notes in its most recent academic program assessment report that each is focused on "putting state-of-theindustry concepts into practice through use-inspired research that is responsive to world challenges and relevant to small, medium, and large industry needs" (Technology, 2012, p. 1). The College underscores that it has "taken the land-grant mission to action through interdisciplinary collaborations, partnerships with industry, community engagement, and physically and virtually taking access to higher education and putting it into the regional and rural sectors of the state," (p. 2) allowing Indiana residents to learn and benefit in a manner that will enable them to become immersed in the global community. It is apparent, 
therefore, that the College considers itself an embodiment of the concepts, such as teaching branches of learning related to the mechanic arts, stated in the Morrill Land Grant Act of 1862 (Morrill Act of 1862).

The Department of Aviation Technology itself serves Purdue's land-grant mission by providing access to its programs through the West Lafayette campus, and through an extended campus in Indianapolis operated by the Statewide College of Technology and shared by Vincennes University, although the flight major is not delivered at the Indianapolis location. Purdue is one of three institutions in the State of Indiana classified by the Carnegie Foundation as RU/VH, and the only such institution offering aviation technology programs. It is the only institution of higher learning in Indiana to offer a full complement of these programs to include Aviation Management, Professional Flight, and Aeronautical Engineering Technology. Purdue's aviation programs are generally recognized within the industry to be within a top tier of similar programs offered by peer institutions such as The Ohio State University, Arizona State University, and others.

Although enrollment in in the College of Technology declined by 7.7 percent over a three-year period from Fall 2009 through Fall 2011, undergraduate enrollment in the Professional Flight Technology program increased by nine percent over the same period, a trend which runs counter to not only the College enrollment trend, but the overall University enrollment trend, as well. Admissions into the program are currently managed to achieve a maximum cohort size of 72 students once a year in the fall semester, a metric that is largely driven by available flight slots. This paper examines the opportunity for improving the utilization of existing training aircraft to enable increased student enrollment and reduced student flight fees.

\section{Examining Aircraft Utilization}

Purdue University employs 16 Cirrus SR-20 aircraft in the primary portion of its Professional Flight program; while four Piper Arrow aircraft are used for a small portion of the Instrument / Commercial courses, the SR-20s account for 95\% of the total student flight time in the primary flight courses and are therefore the only aircraft considered in this utilization study. A recent examination of utilization data for the Cirrus portion of the fleet indicated an average aircraft utilization rate of $26.25 \%$ during normal operating times of the training facility over a period extending back to the beginning of the Fall 2014 semester. An improvement in the efficiency of the scheduling of the Cirrus fleet would allow an accurate determination of the degree of excess capacity in the system. This excess capacity should ideally be treated as an asset that could be used to support an increase in enrollment in the flight training program. By spreading the fixed costs of the program across a larger number of students, the course fees for the program could be potentially decreased, thereby improving the overall affordability of the program. This would not only contribute to reversing the enrollment decline in the College of Technology, but also assist the University in meeting President Daniels' goal of improving affordability for all Purdue students (Daniels, 2014; Daniels, 2015). 
As noted in the previous section, utilization of Purdue's fleet of Cirrus training aircraft tends to average below $30 \%$. While the term "utilization" can be defined in different ways, and is dependent on the exposure basis, it is apparent that there is an opportunity to increase the operational efficiency of the Purdue training fleet through improvements in the scheduling process. The exposure basis used for the present calculations covers a period from 7:30 am to 7:30 pm (with some exceptions that will be described later), Monday through Saturday, during the regular academic semester and excluding academic holidays. Total weekly schedulable hours (WSH) are given by Equation 1 .

$$
W S H=A * D * S * L,
$$

where

$A$ is the number of aircraft in the fleet,

$D$ is the number of days per week that flight training is scheduled,

$S$ is the number of flight slots in a flight training day, and

$L$ is the length of a flight slot in hours.

For the Fall 2014 semester, which covers the period August 25 to December 20, $A=$ $16, D=6$, and $L=2$. During the portion of the semester from August 25 through November $1, S=6$, while during the portion extending from November 2 to December $20, S=5$. This reduction in $S$ midway through the semester is due to lack of availability of the 1730 flight slot because of the change from Daylight Savings Time to Standard Time. The weekly utilization of Purdue's Cirrus fleet is depicted in Figure 2. A description of the utilization categories shown in Figure 2 is in the following sections.

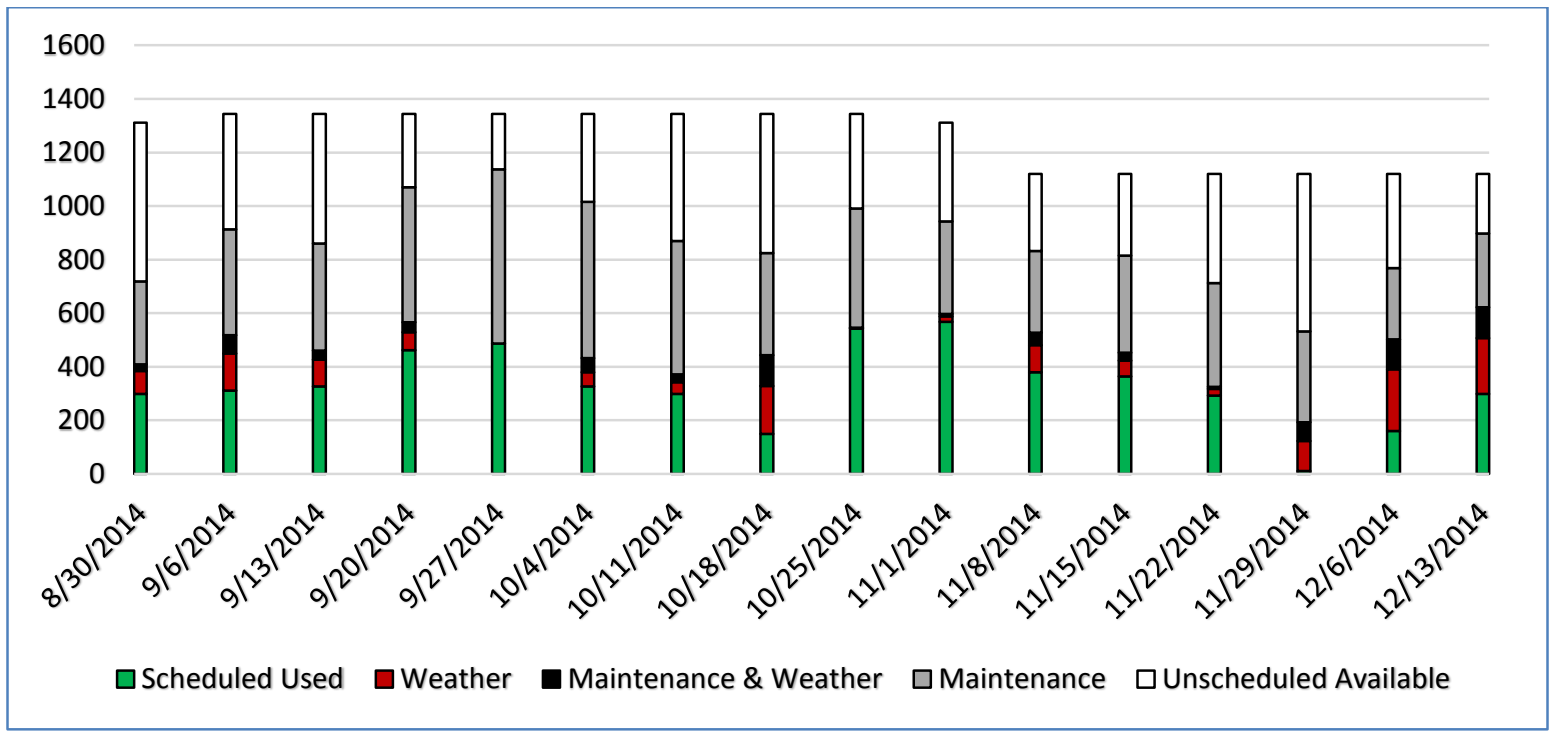

Figure 2. Weekly Cirrus utilization (hours), Fall semester, 2014. 
Scheduled used: The total amount of time for which aircraft were dispatched for potential use. This is not equivalent to either Hobbs time (time during which the aircraft electrical system was in operation) or Tachometer time (time during which the aircraft's engine was operating), but simply the time between check out and check in of the aircraft. It is assumed that as soon as the aircraft is dispatched, it is being used by the individual to whom it is dispatched, and that no one else would have access to the aircraft for the duration of the dispatched period, regardless of whether or not the aircraft actually flew.

Weather: Aircraft are unflyable due to the most restrictive weather minimums not being met. Note that the pilot in command is the final authority regarding whether a flight can be initiated, so time will occasionally be recorded as "Scheduled used" while weather minimums are not actually met.

Maintenance and Weather: This utilization category occurs while an aircraft is down for maintenance and the weather minimums are also not met. The hours in this category are generally small (approximately five percent of total Cirrus time).

Maintenance: An aircraft is unable to be dispatched because it is either in a maintenance queue awaiting maintenance or having maintenance performed.

Unscheduled Available: The aircraft is not scheduled to be used and is available to be dispatched. Such aircraft are generally positioned on the ramp or in a hangar.

The efficiency problem can be further decomposed into challenges related to supply and challenges related to demand. Each of these are examined in the following sections.

\section{Scheduling Inefficiencies Related to Supply}

Two overall hard scheduling constraints are imposed by weather and by operating hours, as follows:

1. Weather minimums in terms of ceiling and visibility are set by Federal Aviation regulations and by best practices in collegiate flight training operations. These minimums are inviolable.

2. Operating hours tend to follow daylight patterns, since almost all primary flight training and much (but not all) advanced training needs to occur in the daytime.

There are a number of scheduling constraints which lead to reduced efficiencies and which appear to be controllable. Such dispatch-related constraints include: 
1. Inflexible flight training blocks that last two hours each. A portion of this time is used for briefings that could be more efficiently conducted during separate ground periods. The schedule blocks follow University-imposed slots for course section times.

2. Operating hours are set to cover times during official daylight hours. This is an administrative policy decision.

Maintenance-related constraints include:

1. Administratively-decoupled maintenance scheduling and weather-imposed flight restrictions. As a result, there are missed opportunities to perform routine maintenance when aircraft are close to required hourly maintenance points and weather conditions are worse than the most restrictive weather policy guidelines.

2. An indeterminate maintenance queue; i.e., an uncertain amount of time between the point an aircraft is removed from service and the starting time of maintenance performed on the aircraft.

3. Lack of maintenance service availability at times when aircraft would not normally be operated. Maintenance operations are conducted during a single shift. No maintenance service is available at night. This is due to departmental administrative policy and overtime pay considerations.

\section{Scheduling Inefficiencies Related to Demand}

There are three cyclical utilization patterns that are apparent:

1. A daily pattern in which the demand for early morning flight slots and late afternoon flight slots is not as great as that for slots in the middle of the day. This could be the result of a propensity on the part of students or academic schedulers to establish a regular slot that will not be as greatly affected by early morning fog and afternoon thunderstorms. This pattern is evident from Figure 3, which shows average scheduled hours per flight slot during the Fall 2014 semester. The peak slot utilization of approximately $33 \%$ occurs from the 1130 through the 1530 slots. Note that each slot is averaged over the full semester with the exception of the 1730 slot, which is averaged only over the portion of the semester in which daylight savings time is in effect; this will be explained in the following section. 


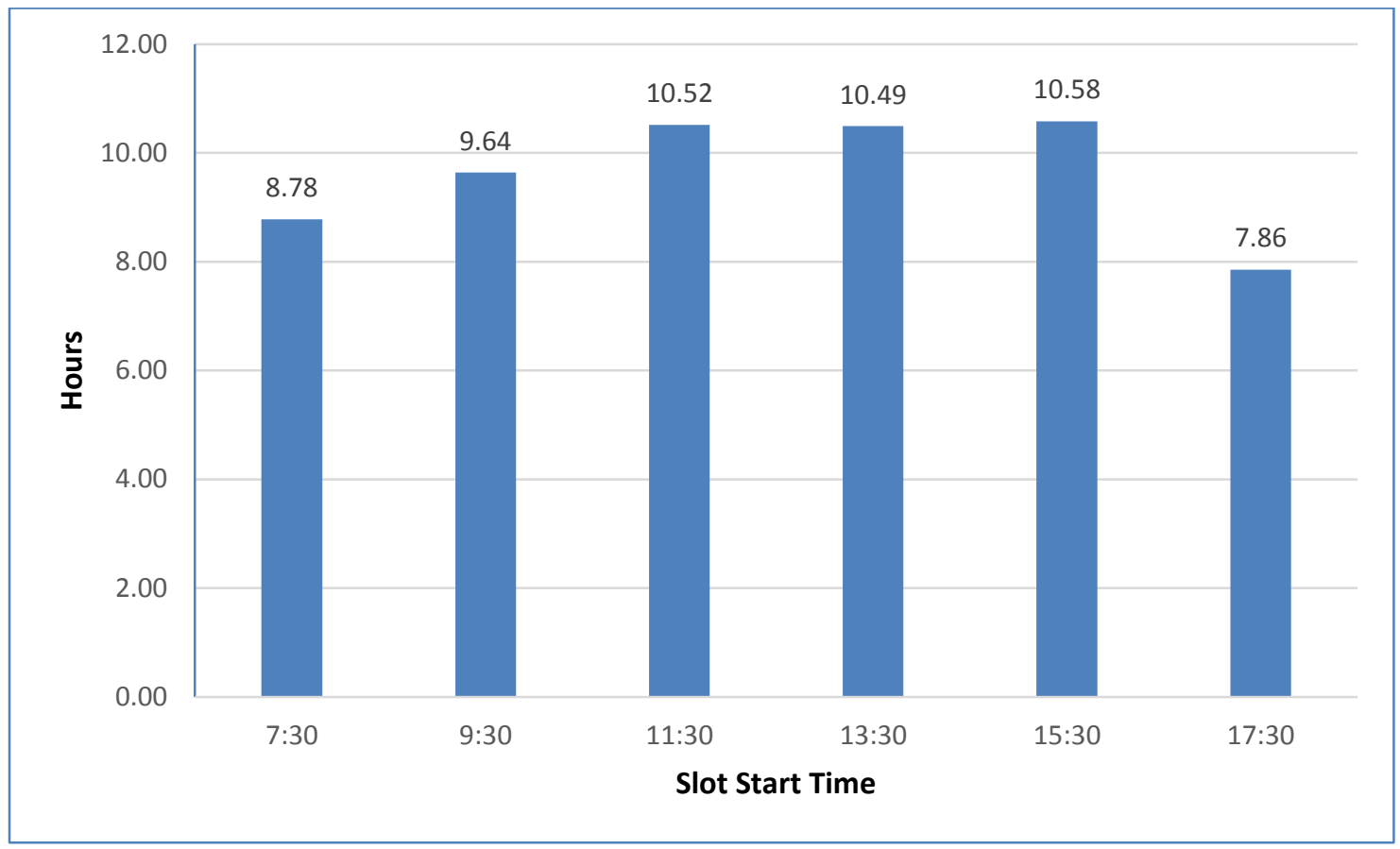

Figure 3. Daily scheduled Cirrus hours by flight slot, Fall 2014 semester.

2. A weekly pattern in which slots on days in the middle of the week are in greater demand than slots at the beginning and end of the week. This data is depicted in Figure 4.

3. A semester-long cycle in which demand tends to increase as the semester progresses, peaking around week 10. This cycle is particularly disruptive in the fall semester, since it would tend to coincide with a general decrease in the number of hours available for which weather conditions are sufficiently greater than minimum limits for flying as that semester progresses. 


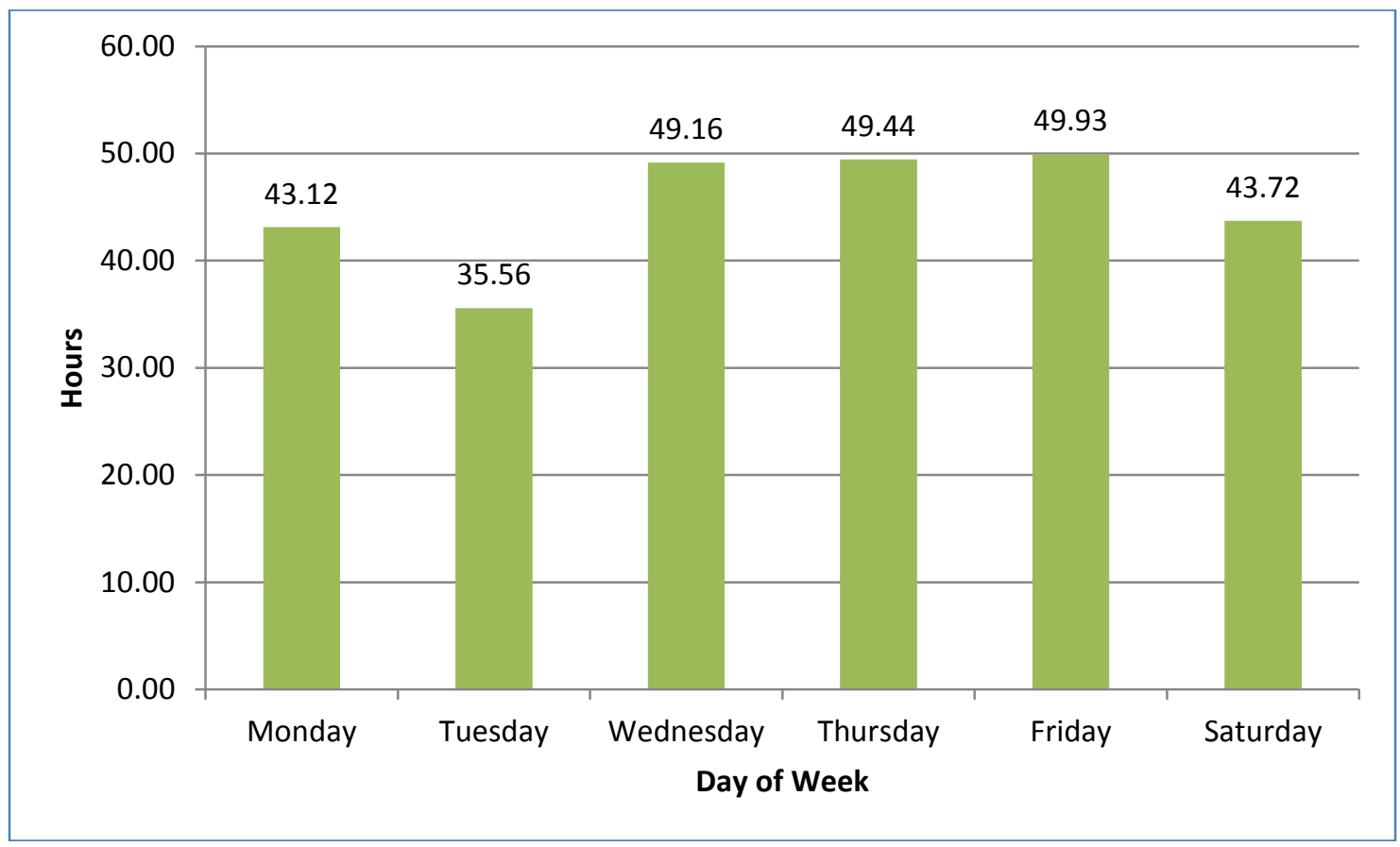

Figure 4. Scheduled Cirrus hours by day of week, Fall 2014 semester.

\section{Potential Opportunities to Improve Utilization}

The present research is primarily oriented to improving the demand side of the overall training system. It is anticipated that future research will focus on the supply side. With that said, a brief discussion of opportunities related to both sides of the system is in order.

Opportunities to improve the supply side of the overall system could potentially impact both the flight scheduling and dispatch operation and the maintenance operation. A solution to the limitation in supply imposed by what are apparently longer than necessary scheduled flight periods could be the reduction of the schedule block length for the aircraft; i.e., the establishing of more, shorter schedule blocks for the aircraft. As determined through a conversation with the Office of the Registrar, these aircraft schedule blocks do not necessarily have to follow the class blocks that are standard at the University level, although they currently do so. An additional solution to supply constraints from the flight scheduling and dispatch perspective is the shift of some advanced training slots to nighttime hours. As noted previously, almost all operations are currently conducted during daylight hours.

There appear to be opportunities present to shift some maintenance activities when aircraft are close to scheduled maintenance intervals such that maintenance can be performed during unflyable weather. For example, if an aircraft is scheduled to receive a phase inspection at 100 hours and a period where weather conditions are expected to be 
unflyable for the next 36 hours is being entered, it would be desirable to proceed with the scheduled maintenance 0.5 hours advance of its scheduled time. This initiative could be combined with an opportunity to communicate current and forecast maintenance queue lengths to administrative stakeholders in order to identify future windows where there is a need to schedule overtime maintenance activities.

An important component of the overall flight time supply inefficiency is the lack of maintenance capacity at times when the demand for the aircraft is low or nonexistent; i.e., during the period from 7:30 pm until 7:30 am. That maintenance capacity could be greatly increased by instituting an additional shift of personnel, comprised of a supervising airframe and powerplant-certified (A\&P) mechanic and a number of students in the Aeronautical Engineering Technology program who are either studying to obtain their A\&P certification or who have received it as seniors. There also exist opportunities to schedule some maintenance activities outside of peak flight times during regular shifts. It may be possible to schedule maintenance staff such that a greater portion of their schedules would fall in either the early morning hours or late evening, thereby shifting capacity such that it is available when the demand for aircraft is lower.

\section{Flight Slot Demand Management}

Inefficiencies noted previously that are related to fluctuating demand on both diurnal and semester cycles can also be addressed. Each of these cyclical patterns could likely be modified by incentivizing students to fly during the less-preferred times. A reduction of flight rates could be implemented, thereby improving utilization in early mornings and late afternoons, as well as during slack times of the semester. In order for this to be successful, one must assume that a supply/demand relationship exists and that student selection of flight slots is relatively elastic with regard to economic behavior. By smoothing demand across daily time slots and across the semester through the use of modest pricing incentives, previously unused slots could be converted into scheduled hours.

According to Avery (2014), student flight slots at Purdue are subject to the following scheduling constraints:

- Flights are scheduled within blocks that are two hours long.

- Hours of operation are from 7:30 a.m. to 5:30 p.m. for eight weeks and 7:30 a.m. to 7:30 p.m. for the other eight weeks, seven days a week (Sundays are optional). The 5:30 p.m. slot is available only when daylight savings time is in effect.

- Night flights occur four days a week but are used only to complete lesson plans.

Currently, students are assigned to flight slots by administrative personnel. Slot times and days of the week do not change throughout the semester. A total of four flight courses utilize the Cirrus fleet. Three of the courses (AT 14500, AT 24300, and AT 24800) are scheduled across three days of each week during the semester: Monday, Wednesday, and Friday, or Tuesday, Thursday, and Saturday. The remaining course (AT 25300) is scheduled across two days of each week: Monday - Friday, Tuesday - Thursday, or 
Wednesday - Saturday. Sundays are used as opportunities to allow students to make up slots that were missed during the week.

It is proposed that the slot assignment procedure be changed to allow students to select slots. Presumably, early and late slots have been underutilized due to schedule conflicts encountered by students enrolled in ROTC programs, which tend to have early morning meeting requirements, and co-curricular activities such as marching and concert band, which tend to meet later in the day. The proposed change will allow students to make their own scheduling decisions within a market economic context, and with monetary incentives to select what might be viewed as less desirable slots.

It should be noted that slot no-shows account for a relatively low percentage of unused flight slots. Purdue does not currently penalize students for no-shows; there appears to be little motivation to initiate such a procedure at this point.

\section{Higher Education Pricing Elasticity Literature}

Although little or no research related to price elasticity of demand in flight training or in college course fees exists, there is a body of research related to elasticity in both college tuition rates and college textbook purchases. While neither of these elasticities should be expected to be equivalent to that which might be expected as a student response to decreased (or increased) flight course fees, they can at least provide a reference point to allow the establishment of a baseline for the purposes of the current research.

Leslie and Brinkman (1987) conducted an empirical review of 25 studies that examined student higher education enrollment elasticity in response to tuition changes that had been published as of the date of their research, and presented, in a standardized format, an estimate of the student-price response coefficient (SPRC), a percentage change in enrollment per $\$ 100$ tuition price change, for each. The SPRC can be converted to an elasticity by multiplying it by $\$ 100$ and dividing by $P$, the percentage change in price. While all of these studies examined enrollment responses of first-time students in response to tuition changes, they arrived at relatively consistent results, with SPRCs ranging from 0.5 to -1.3 . It should be noted that the Leslie and Brinkman research examined studies that considered only first-year enrollment; elasticity of continuing students was not investigated. A review by Heller (1997) examined more recent studies and confirmed the findings of Leslie and Brinkman, indicating an SPRC range of between -0.5 and -1.0.

A study authored by Bryan and Whipple (1995) develops a tuition pricing model that is "useful in predicting the retention rate of current students at increasing tuition rates" ( $p$. 561). The distinction between the Bryan and Whipple study and those of Leslie and Brinkman (1987) and Heller (1995) is that it examines current students, rather than firsttime students. None of these studies focuses specifically on enrollment in single courses, instead examining overall institutional enrollment; however, while "this is an aggregate effect and may differ for individual institutions or groups of students ..., as a whole, this 
fundamental relationship - the existence of a downward-sloping demand curve found by Leslie and Brinkman and other researchers - has been confirmed" (Heller, 1997, p. 650). According to Heller, the consensus among the studies reviewed is that the SPRC values between -0.5 and -1.0 are consistent "across all types of institutions."

Two additional recent studies provide separate measures of elasticity in the form of regression coefficients. Research investigating elasticities among first-year, first-time students at four-year institutions in Colorado during the $2004-2010$ period (Augenblick, Palaich, 2012) indicated a mean odds ratio on net price per $\$ 1000$ change in tuition to be 0.966. This can be converted into both an elasticity coefficient and an SPRC with the information provided in the study. The odds ratio implies a percentage change in enrollment given a $\$ 1000$ tuition change of 3.4\% (1-0.996). Since the SPRCs in the previous research employ a base price change of $\$ 100$, this value equates to an SPRC of 0.34 , which is in line with those studies, albeit at the low end of the range, and which may indicate that student behavior is becoming somewhat less elastic over time. The SPRC can, in turn, be converted to a pure elasticity coefficient, $\varepsilon$, where

$$
\varepsilon=\frac{\Delta E}{\Delta P}
$$

$E$ is enrollment, and $P$ is price, by using the mean tuition price across Colorado institutions across the study period, $\$ 15,299$. This results in $\varepsilon=-0.52$. Another study of tuition elasticity at Florida Southern College (Brown, McClary, \& Bellingar, 2012) does not provide sufficient information such that an SPRC can be calculated; however, the elasticity coefficient provided by that study is -1.2 , which seems high, but a separate coefficient applicable for non-Florida residents only was determined to be -0.29 , which is more in-line with the Colorado data. These values of $\varepsilon$ are also consistent with a recent study using data from the Integrated Postsecondary Education Data System covering the period from 1991 to 2007 (Hemelt \& Marcotte, 2008), which indicated an elasticity coefficient of -0.1072 .

Chevalier and Goolsbee (2003) used publicly-available data on prices and sales ranks of books listed by online book retailers Amazon and Barnes \& Noble to determine price elasticities of demand for those retailers' products. They did so by developing a method of converting sales ranks into sales quantities for 18,000 different books. Their results showed elasticities of -4.0 and -0.6 for BN.com and Amazon.com, respectively, indicating a much higher elasticity for Barnes \& Noble than for Amazon. Note that the elasticities here, which are representative of a more general population, might be expected to be somewhat higher than for those representative of college students, since the latter tend to be a far more captive audience. Koch (2007) noted that student textbook demand is relatively price inelastic. Chevalier and Goolsbee (2005) later extended their research to focus specifically on the college textbook market. Their findings from this investigation indicated an elasticity of -0.9 for students purchasing textbooks for which a revision is not expected (a stable market), and one of -3.7 in situations for which a revision is certain to 
occur (an unstable market). Note that the stable market elasticity determined from the 2005 study by Chevalier and Goolsbee is in line with those found in the enrollment studies examined previously.

\section{Application of Pricing Principles to Manage Flight Slot Demand}

The first step in the process for smoothing slot demand is the adjustment of hourly rates for slots. One must first assume an appropriate price elasticity of demand coefficient for student slot enrollment in response to hourly rate changes. Based on the preceding literature review, a value of -2.0 for $\varepsilon$ seems reasonable, due to the changes in the slot assignment procedure of which all students will be made aware. From Figure 3, the average daily scheduled time across all slots is 57.87 hours. Using a weighted average to allocate this time across the five slots that are unaffected by the change to standard time and the one slot that is, one obtains a target value of $5.625 \mathrm{x}=57.87$, or $\mathrm{x}=10.288$, which represents the average daily scheduled time per slot. It is reasonable, then, to incentivize students to enroll in both the 0730 and the 1730 slots, since those slots fall somewhat below the average in terms of scheduled hours. This suggests a percentage change in hours of $17.1 \%$ for the 0730 slot and $30.9 \%$ for the 1730 slot. The ratio of actual Hobbs time accumulated on an average aircraft, $T_{H}$, to scheduled time for that aircraft, $T_{S}$, is

$$
\frac{T_{H}}{T_{S}}=70.3 \%
$$

Therefore, the nominal rate of $\$ 210$ per flight hour can be adjusted downward by this amount to compensate for the fact that one scheduled hour translates to only 42 minutes of time in which the average aircraft is actually utilized. This yields an effective rate of $\$ 147.63$ per scheduled hour, suggesting a student flight rate decrease of $\$ 12.62$ per hour for the 0730 slot and $\$ 22.81$ for the 1730 slot.

Once the new hourly rates for each flight slot have been set, the transition to a marketdriven scheduling approach will commence. Undergraduate students at Purdue University register for course sections based on the academic classification to which they belong. Prioritization is in decreasing order of classification, starting with seniors. The registration holds which were previously used to ensure that students selected the flight slots to which they were assigned administratively will be removed. In addition, the slot rates, which include incentives for those slots discussed above, will be made available to all flight students. Students will then be assumed to select slots on the basis of chronological and economic preference within their academic classification groups.

\section{Flight Slot Supply Management}

The second portion of the work needed with regard to scheduling of flight slots is related to the supply side of the equation. It was noted previously that constraints on scheduling of flight slots contribute to the overall inefficiency of the process. Because of 
the fact that a portion of the scheduled flight slot is actually used for pre- and post-flight briefing activities that better lend themselves to separate briefing slots that do not require the use of an aircraft, it is proposed that slot length, $L$, be reduced from 2.0 hours to 1.5 hours. This would then provide eight slots per day: 0730-0900, 0900-1030, 1030-1200, 1200-1330, 1330-1500, 1500-1630, 1630-1800, and 1800-1930.

It is instructive to examine the current path that students follow through the Professional Flight program in order to better understand the constraints that are present. These constraints are an impediment to expanding the overall enrollment of students in the program. Figure 5 depicts the program flow in a flow diagram format.

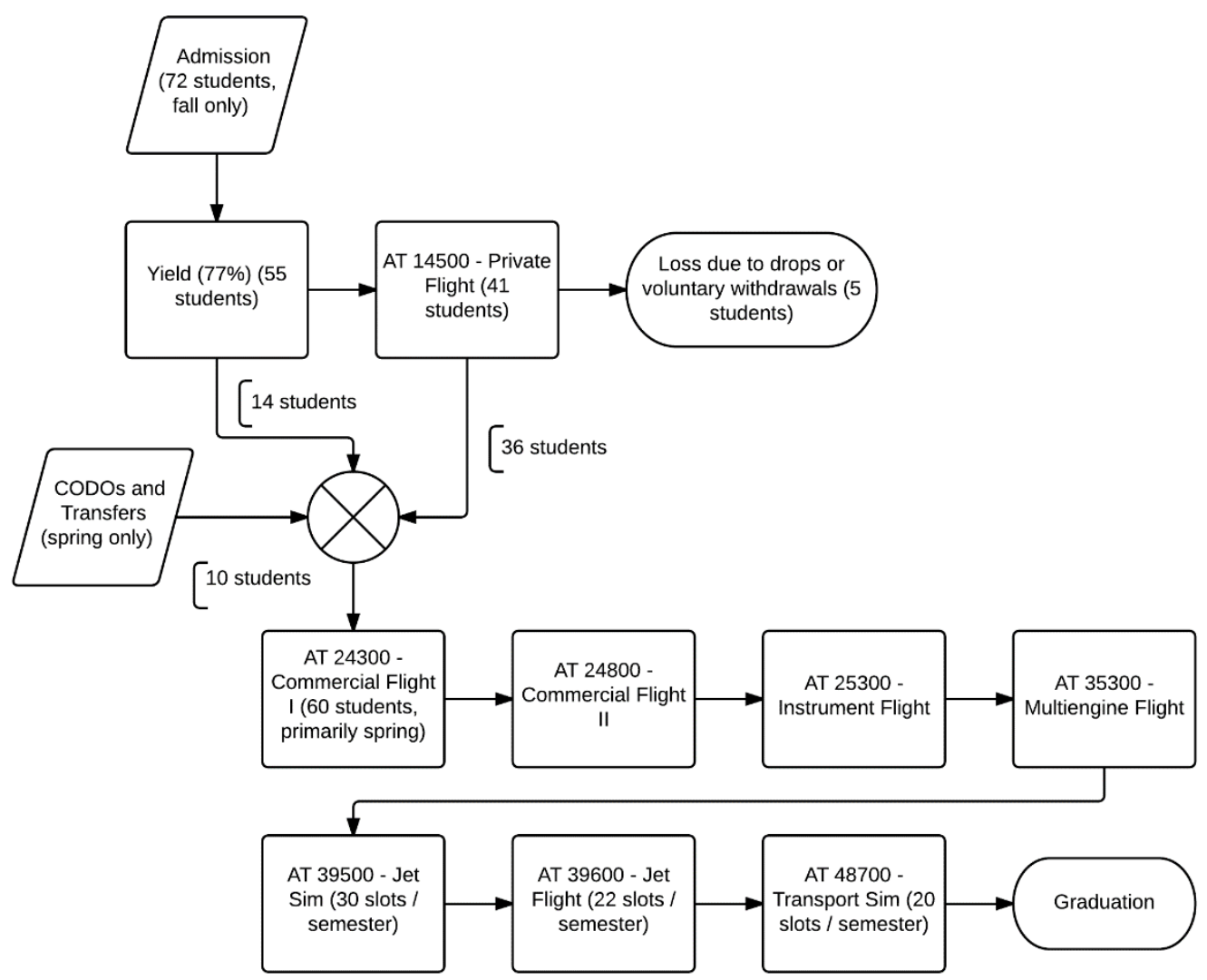

Figure 5. Critical path analysis of Professional Flight Program that shows constraints in system.

Two restrictions to student flow that are readily observed from the flow diagram are related to the Private Flight course (AT 14500) and in the Advanced Transport Category Flight course (AT 39600). The latter restricts student flow due to the limited number of slots available for the Embraer Phenom 100 jet training aircraft. Solutions to that issue involve potential fleet additions and are pending. The scope of the current research is 
limited to improving flow through the Private Flight course in order to mitigate what is currently perceived as a flow restriction through that course.

Further motivation for implementing changes to improve Cirrus flight slot supplies may be derived from estimates of the potential for additional program revenue resulting from increased student enrollment. First, assume that all maintenance can be performed in such a manner that only two aircraft are out of service for maintenance reasons at any given time. If one assumes that eight slots per day are available over seven days per week, an increase of either two or three slots over the current situation, depending upon the time of year, and that two of the sixteen Cirrus aircraft are designated as maintenance reserve aircraft, there are 784 total available slots during a given week. Unflyable weather averages 72 hours per week, or 48 slots. This leaves 736 slots per week, on average, that are schedulable. The number of weekly slots required per flight course is shown in Table 1.

Table 1

Number of weekly slots required per course

\begin{tabular}{lc} 
Flight Course & Number of Slots \\
\hline Private Pilot Flight & 3 \\
Commercial Flight I & 3 \\
Instrument Flight & 3 \\
Commercial Flight II & 2 \\
\hline
\end{tabular}

The total number of weekly slots required for all primary flight courses is then 11 slots. With 736 available weekly slots, this equates to 67 enrolled students across all four primary flight courses. For admissions purposes, assuming a $77 \%$ average yield, this translates to 87 admitted students each fall.

As noted in Figure 5, the primary flight courses enroll an average of 55 students each fall. The proposed increase in enrollment from 55 to 67 students is a $21.8 \%$ increase. The incremental revenue resulting from that increase, as determined from rates published by Purdue's Office of the Bursar and assuming that $74.5 \%$ of incoming students will enroll initially in AT 24300 due to previously having received their Private Pilot certificates, is shown in Table 2. 
Table 2

Incremental Program Revenue Due to Proposed Enrollment Changes

\begin{tabular}{llrlrr} 
Semester & AT 14500 & AT 24300 & AT 24800 & AT 25300 & Total \\
\hline Fall 2015 & $\$ 91,521$ & $\$ 32,271$ & & & $\$ 123,792$ \\
Spring 2015 & & 129,084 & & & 129,084 \\
Fall 2015 & 91,521 & 32,271 & $\$ 129,084$ & & 252,876 \\
Spring 2016 & & 129,084 & & $\$ 129,084$ & 258,168 \\
\hline
\end{tabular}

The asymptotic revenue, then, once the additional student flow has propagated through the first two years of the flight program, is $\$ 258,168$. The 2014-15 program revenue from Cirrus operations was projected to be $\$ 2,262,625$. If one assumes an aircraft fleet valuation of book value less accumulated reserves, and calculates the capital turns ratio as the ratio of the sum of the projected Cirrus revenue and the incremental revenue increase due to the additional program enrollment to the fleet valuation, the figure of $72.95 \%$ is obtained. The capital turns ratio without the incremental revenue increase is $65.47 \%$. This suggests an increase in capital turns of just under $7.5 \%$ due to the additional program revenue.

Because a portion of the incremental increase in revenue related to the addition of students in the program is associated with the covering of fixed costs, as opposed to variable costs, a percentage of that portion can be dedicated to lowering overall course fees. The remaining percentage of the revenue increase can be allocated for the purpose of increasing maintenance staffing so as to reduce maintenance downtime.

\section{Recommendations}

It is recommended that enrollment capacity in the Professional Flight program be increased by approximately $20 \%$ beginning in in the $2015-16$ academic year. This is to be achieved primarily through the assignment of students to currently unused flight slots, and secondarily through the addition of new slots, with the slot assignment system transitioning to a market-driven approach with financial incentives for slots that may be less desirable. Revenue increases from the additional enrollment will be used partially to offset fixedcosts, with the potential to lower flight course fees and improve the overall affordability of the program, and partially to fund additions to maintenance staffing levels. Detailed estimates of the total percentage reduction in program fees are somewhat elusive at this early point in the implementation, but indications from the lead author's recent participation in Purdue's biennial budgeting process are for a potential overall decrease in such fees of as much as eight percent.

Maintenance downtime planning meetings are also recommended. These meetings with the maintenance staff will be held in an effort to develop a shared vision with regard 
to increasing fleet availability. The desired outcome from this process will be the development of key performance indicators and metrics that will be useful to maintenance personnel as they seek to improve maintenance efficiency. The Operations Center, an integrated facility staffed by aviation management students and tasked with the assimilation of operational data and operational decision-making, will be engaged to produce reports for maintenance managers based on the key performance indicators.

In addition, a senior-level undergraduate course in aviation managerial economics has been developed by the lead author. This course is being offered in the spring semester of 2015, and will be employed as a means to allow students to participate in the development of additional recommendations to improve fleet utilization and to assist in the implementation and monitoring of those recommendations. This process will serve the dual purpose of facilitating student buy-in to the changes to the scheduling process, and providing students with experiential learning opportunities consistent with the ongoing transformation of the College of Technology into the Purdue Polytechnic Institute (Purdue, 2015).

It is anticipated that these recommendations will enable an increase in operational efficiency in the primary flight program that will both enable the program to accommodate new flight program majors who would not have otherwise been allowed to matriculate, and sustain a reduction in course fees for all enrolled students that will ultimately improve program affordability.

While the recommendations outlined here are designed specifically for primary flight operations at Purdue University, a certain degree of generalizability ensures that they may be considered extensible to other, similar operations. Some of those generalizable concepts include market-driven scheduling in which less-desirable flight slots are incentivized in a manner suggested by price elasticity of demand research, adjustment of slot lengths to better accommodate the time actually spent in operation of the aircraft, and a systemic approach to schedule interactions between dispatch and maintenance operations.

\section{Future Research}

A pilot implementation of the process recommendations described herein is currently in progress. The initial program modifications will consist of financial incentives for lessdesirable flight slots to be implemented and advertised to students during the Fall 2015 enrollment process. Follow-on research designed to measure the effects of the transition to a market-driven slot selection procedure and the slot incentive process, in which the results of the modifications will be compared with current slot assignments to determine the efficacy of the flight slot incentive approach, is planned to commence early in the 201516 academic year, once data is available for study. Also, modifications to the lengths and number of slots are expected to occur in the Spring 2016 semester, with further research to determine the effectiveness of those modifications to be conducted in a subsequent semester. 
In addition, changes to maintenance staffing levels and maintenance scheduling will be investigated in a following semester with the expectation of improving the deficiencies related to maintenance scheduling procedures that were noted previously.

With regard to non-program-specific research potential, there are certainly opportunities to apply the generalizable concepts suggested previously to other collegiate flight programs that seek improvements to utilization efficiency. It is hoped that such research will lead to improvements that will benefit all programs comprising the collegiate aviation community. 


\section{References}

Augenblick, Palaich, and Associates (2012). Price sensitivity in student selection of Colorado public four-year higher education institutions.

Avery, B. K. (2014). An analysis to determine the maximum utilization of Purdue University's aircraft fleet (Unpublished capstone project proposal). Purdue University, West Lafayette, IN.

Brown, C. C., McClary, A., \& Bellingar, J. (2012, July). Determinants of student demand at Florida Southern College. Journal of Case Research in Business and Economics, 1-9.

Bryan, G. A., \& Whipple, T. W. (1995). Tuition elasticity of the demand for higher education among current students: A pricing model. The Journal of Higher Education, 66(5), 560-574.

Chevalier, J., \& Goolsbee, A. (2003). Measuring prices and price competition online: Amazon and Barnes and Noble. Quantitative Marketing and Economics, 1(2), 203-222.

College of Technology (2012). Academic program assessment. West Lafayette, IN: Purdue University.

Daniels, M. E. (2014). An open letter to the people of Purdue. Retrieved from http://www.purdue.edu/president/email/2014/1401-med-openletter.html

Daniels, M. E. (2015). An open letter to the people of Purdue. Retrieved from http://www.purdue.edu/president/messages/1501-med-openletter.html

Heller, D. E. (1997). Student price response in higher education: An update to Leslie and Brinkman. The Journal of Higher Education, 68(6), 624-659.

Hemelt, S. W., \& Marcotte, D. E. (2008). Rising tuition and enrollment in public higher education, Discussion Paper No. 3827. Bonn, Germany: IZA.

Koch, J. V. (2007). An economic analysis of textbook pricing and textbook markets, ACSFA college textbook cost study plan proposal, advisory committee on student financial assistance. Retrieved from http://files.eric.ed.gov/fulltext/ED497025.pdf

Leslie, L.L., \& Brinkman, P. T. (1987). Student price response in higher education: The student demand studies. The Journal of Higher Education, 58(2), 181-204.

Morrill Act of 1862, 26 Stat. 417, codified as amended at 7 U.S.C. $\$ 321$ et seq. 
Office of Enrollment Management (2013). Enrollment, admissions, retention and graduation rates, degrees, and student debt five-year trends. West Lafayette, IN: Purdue University.

Purdue Polytechnic Institute (2015). How does this impact current students? Retrieved from https://polytech.purdue.edu/ 